OPEN ACCESS

Edited by:

Changzhou Yuan,

University of Jinan, China

Reviewed by:

Lijie Ci,

Harbin Institute of Technology,

Shenzhen, China

Yunhua Xu,

Tianjin University, China

*Correspondence:

Limin Chang

changlimin2139@163.com

Ping Nie

pingnie@jInu.edu.cn

Specialty section:

This article was submitted to

Electrochemistry,

a section of the journal

Frontiers in Chemistry

Received: 10 April 2020

Accepted: 27 July 2020

Published: 08 September 2020

Citation:

Guo Y, Li J, Wang H, Chang L, Rui B,

Lin L, Xu T and Nie P (2020)

Aerosol-Assisted Assembly of Mesoporous Carbon Spheres With

Fast and Stable K-ion Storage.

Front. Chem. 8:784.

doi: 10.3389/fchem.2020.00784

\section{Aerosol-Assisted Assembly of Mesoporous Carbon Spheres With Fast and Stable K-ion Storage}

\author{
Yu Guo ${ }^{1}$, Jiahui Li ${ }^{1}$, Hairui Wang ${ }^{1,2}$, Limin Chang ${ }^{1 *}$, Binglong Rui ${ }^{1}$, Li Lin ${ }^{1}$, Tianhao Xu ${ }^{1}$ \\ and Ping $\mathrm{Nie}^{1 *}$
}

${ }^{1}$ Key Laboratory of Preparation and Applications of Environmental Friendly Material of the Ministry of Education, College of Chemistry, Jilin Normal University, Changchun, China, ${ }^{2}$ School of Materials Science and Energy Engineering, Foshan

University, Foshan, China

Cost effective anode material with rational design is of significance for rechargeable potassium ion batteries (KIBs). Graphite anode currently still suffers unfavorable rate capability and moderate cycling stability. In this work, we report a mesoporous carbon sphere with rich porous structure as an anode material for KIBs with the assistance of an aerosol spray technology. The as-developed carbon spheres exhibit a well-defined spherical structure with favorable surface area of $1106.32 \mathrm{~m}^{2} \mathrm{~g}^{-1}$. Furthermore, the effect of different electrolytes on the electrochemical performance of the carbon anode has been investigated systematically. As expected, the carbon material shows excellent potassium storage performance in terms of improved specific capacity of $188.2 \mathrm{mAh}$ $\mathrm{g}^{-1}$, rate capability and prolonged cyclability with a high capacity of $105.3 \mathrm{mAh} \mathrm{g}^{-1}$ after 500 cycles at a rate of $100 \mathrm{~mA} \mathrm{~g}^{-1}$ toward potassium storage in KFSI based carbonate electrolyte.

Keywords: mesoporous carbon spheres, electrolyte, anode, aerosol spray, potassium ion batteries

\section{INTRODUCTION}

There are an ever-growing energy storage demands for high efficiency and low cost to power portable electronics, electric vehicles, and smart grid. In the past two decades, rechargeable lithium ion batteries (LIBs) have drawn significant attention due to their characteristics of high energy density, desirable cycle life and environmentally friendly (Peng et al., 2017; Liu Y. et al., 2019; Li X. et al., 2019; Sun et al., 2019; Wang F. et al., 2019; Chen et al., 2020). It is currently highly desirable to develop alternative battery systems with low cost and excellent cyclability to meet the increasing demand due to the limited resources of lithium and their uneven global distribution. Potassium locates within the same group in the periodic table with lithium, which exhibits similar chemical properties with the Li element. As a new energy storage device, potassium ion batteries show great potential for large scale application because of the abundant reserves of potassium resources in the earth's crust as well as a lower redox potential of $\mathrm{K} / \mathrm{K}^{+}$ $\left(-2.93 \mathrm{~V}\right.$ vs. SHE) compared with $\mathrm{Na} / \mathrm{Na}^{+}(-2.71 \mathrm{~V})$, thus a wider potential window and higher 


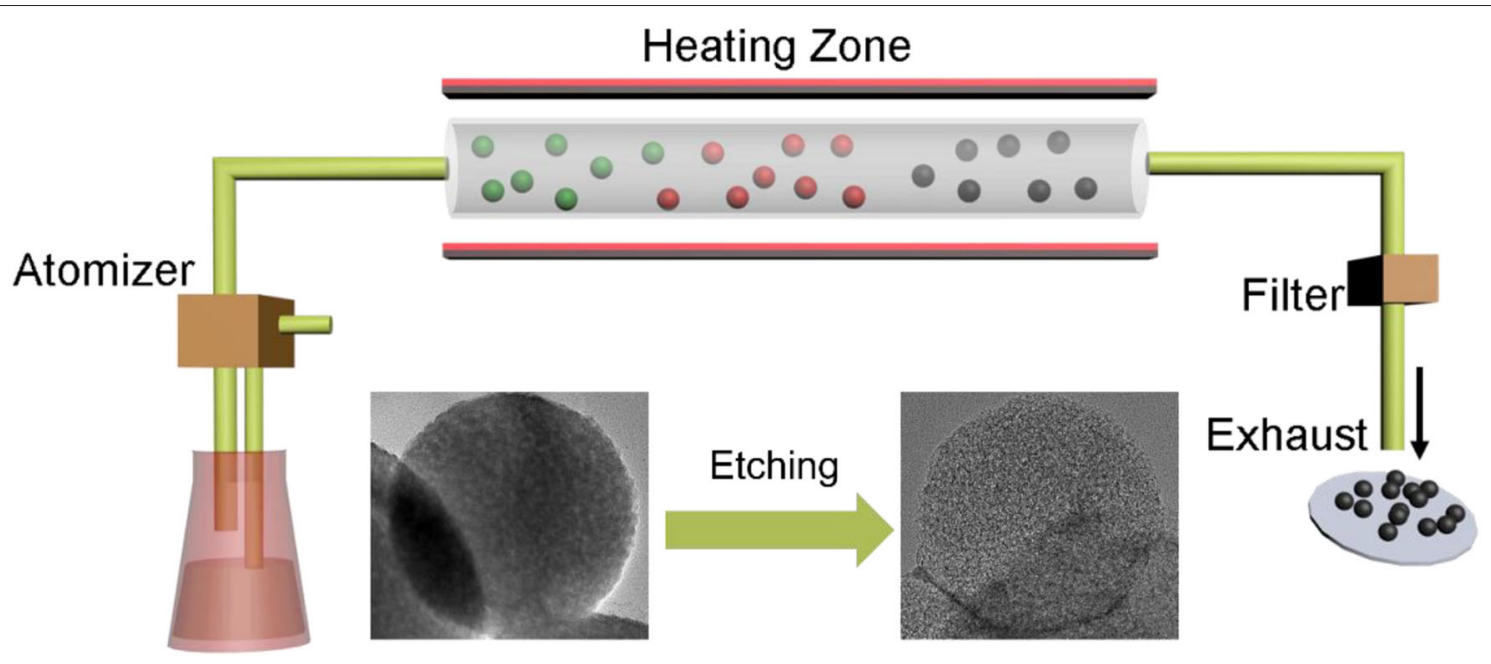

GRAPHICAL ABSTRACT | Aerosol-assisted assembly of mesoporous carbon spheres as anodes for K-ion batteries.

energy density could be achieved (Le et al., 2017; Wu et al., 2017; Jiang et al., 2019; Li L. et al., 2019; Liu et al., 2019a; Zhang R. et al., 2019; Hosaka et al., 2020). Unfortunately, the relatively large radius of $\mathrm{K}^{+}$(1.38 vs. $0.76 \AA$ of $\mathrm{Li}^{+}$) leads to sluggish kinetics and poor cycling performance for most electrode materials in KIBs.

As compared to LIBs, the research on potassium ion batteries is still in its infant stage. Great efforts have been made to develop suitable host material with enhanced the $\mathrm{K}^{+}$insertion/extraction kinetics. Currently, various electrode materials such as carbon materials ( $\mathrm{Hu}$ et al., 2020; Liu M. et al., 2020; Zhang et al., 2020), alloys (Zhang et al., 2017; Lei et al., 2018; Zheng et al., 2019), metal oxide/sulfides (Li et al., 2020a; Liu Y. et al., 2020; Zhou et al., 2020), titanium based insertion materials (Sultana et al., 2016; Dong et al., 2018), and MXene (Okubo et al., 2018; Tang et al., 2020; Zhao et al., 2020) have been extensively studied as promising anodes for K-ion storage. Benefiting from the abundant resources, low cost, allotrope, and excellent physical/chemical stability, carbon materials have been widely reported and used for KIBs (Jian et al., 2015; Liu et al., 2019b; Zhang R. et al., 2019; Huang et al., 2020; Li et al., 2020b). The application of carbon based material for potassium ion storage requires high conductivity and large interlayer space for large $\mathrm{K}^{+}$ insertion. Commercially available graphite has been investigated as anode materials for KIBs with a theoretical capacity of 279 $\mathrm{mAh} \mathrm{g}^{-1}$ based on reversible $\mathrm{KC}_{8}$ phase formation (Komaba et al., 2015; Luo et al., 2015). However, the material suffers from moderate cycling stability and unfavorable rate capability owing to large volume expansion $(\sim 58 \%)$ during $\mathrm{K}^{+}$insertion. Therefore, the remaining issues existed in carbon materials for KIBs including limited reversible capacity and poor cycling stability need to be addressed.

Aerosol-spray shows great potential as a promising technology for the preparation of advanced functional materials for various application ( $\mathrm{Lu}$ et al., 1999; Nie et al., 2018a). Aerosol-spray process mainly includes three steps: atomization, droplet to particle conversion, and product collection (Nie et al., 2017, 2018a,b). The synthesis begins with a liquid solution or suspension as a precursor, then desired material can be obtained through a simple and fast process, which is easy to produce electrode materials in scale. This method combines the advantages of both gas phase and liquid phase synthesis. By changing the process parameters such as precursor concentration, carrier gas flow rate, reaction temperature, and residence time, products with different sizes and morphologies can be prepared. Compared to other methods, aerosol-spray technology exhibits the great advantages in the preparation of materials for energy storage, where electrode materials with a rich porous structure and adjustable size can be obtained. The perfect structure obtained by aerosol is beneficial to ion transfer, increasing the electrolyte contact area, and accommodating volume change during cycling.

Herein, we have designed and fabricated a mesoporous carbon sphere (MCS) with rich porous structure as an anode material for potassium ion batteries with the assistance of an aerosol spray technology. Commercial available silica colloidal was chosen as a template because of its good dispersibility and nanosized particles with a size of 10$20 \mathrm{~nm}$. The carbon sphere exhibits a well-defined spherical structure with favorable surface area. Furthermore, the effect of different electrolytes on the electrochemical performance of the porous carbon has been investigated. As expected, the mesoporous carbon shows excellent potassium storage performance in terms of improved specific capacity of 188.2 $\mathrm{mAh} \mathrm{g}^{-1}$, rate capability, and prolonged cyclability in KFSI based carbonate electrolyte.

\section{RESULTS AND DISCUSSION}

The mesoporous carbon spheres were prepared by a simple aerosol-spray pyrolysis technology as described in our previous 


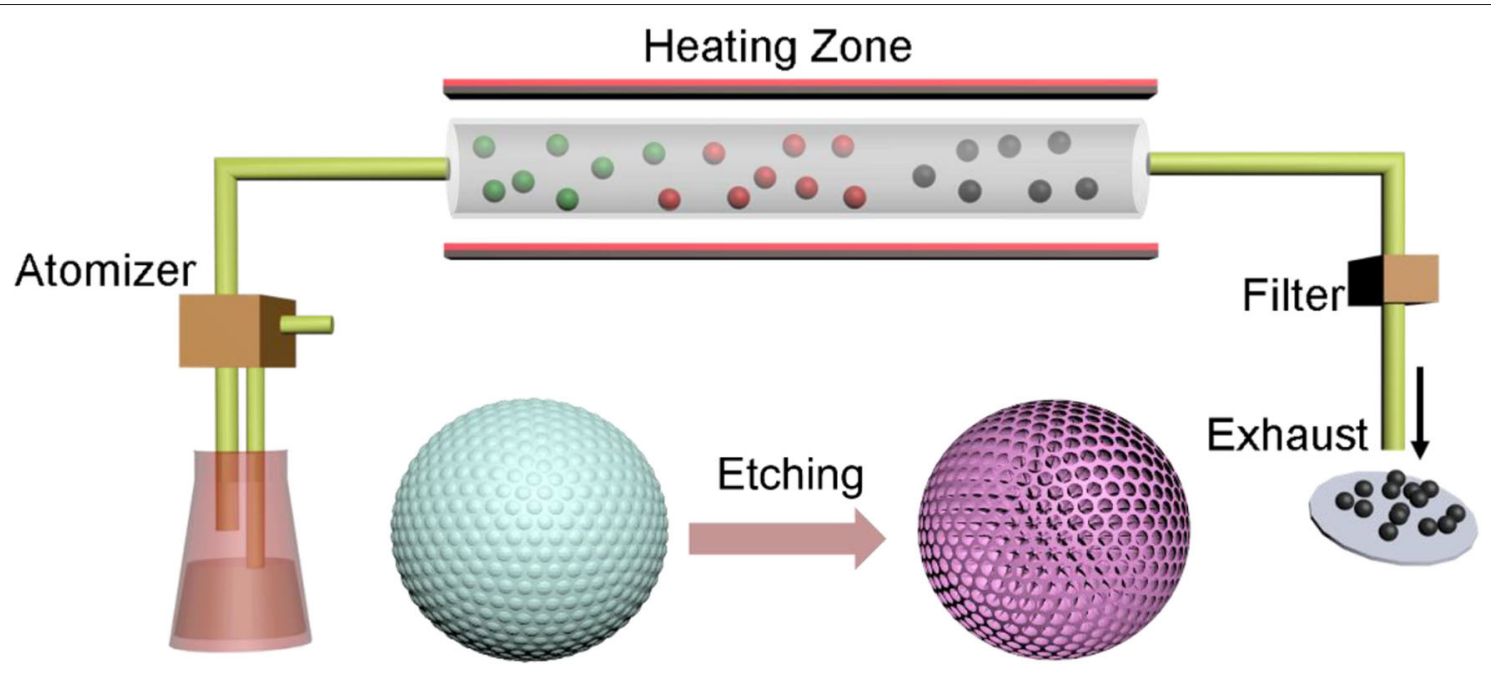

FIGURE 1 | Schematic illustration of the preparation of mesoporous carbon spheres by aerosol-spray pyrolysis technology.

work with colloidal silica and sucrose as precursors (Nie et al., 2017, 2018a,b; Liu X. et al., 2018), as shown in Figure 1. The precursor solution experienced an aerosol spraying process and subsequent carbonization under nitrogen flow at $900^{\circ} \mathrm{C}$ to derive the $\mathrm{SiO}_{2} /$ carbon spheres. Then, the final mesoporous carbon spheres were obtained by removing the silica templates using dilute hydrofluoric acid (HF) etching.

Field emission scanning electron microscope (FESEM) and transmission electron microscopy (TEM) were performed to investigate the structural features of the as-prepared MCSs. It can be seen that well-defined spherical $\mathrm{SiO}_{2} / \mathrm{C}$ particles with a size ranging from $100 \mathrm{~nm}$ to $2 \mu \mathrm{m}$ were successfully synthesized by aerosol spraying process followed by carbonization in an inert atmosphere (Figure 2a). TEM image of $\mathrm{SiO}_{2} / \mathrm{C}$ spheres confirms their typical porous structure consisting of small primary nanocrystals with an average size of $c a .10 \mathrm{~nm}$ (Figure 2c). After annealing at high temperature, the original spherical morphology was well-maintained with a negligible size change even upon acid etching (Figure 2b), indicating superior structure stability of the carbon particles. Further characterization shows the resulting carbon spheres exhibited more substantial porosity (Figure 2d), which was generated by the removal of the silica templates. Such a perfect porous spherical structure can not only increase the tap density of the carbon material, but also facilitate the fast ion/electron transfer, and effectively accommodate volume expansion upon $\mathrm{K}$-ion insertion.

To get further insight into the structure of the MCS, XRD patterns, and Raman spectra of the $\mathrm{SiO}_{2} / \mathrm{C}$ composite and the MCS were collected. As shown in Figure 3A, two broad peaks located at 22.1 and $43.3^{\circ}$ can be observed for the MCS, which can be indexed to the (002) and (101) diffractions, typical characteristic peaks of carbon materials, indicating that porous carbon has been successfully obtained via the aerosol spray. Raman spectroscopy is another powerful and widely used tool to characterize the structural properties of carbon based materials.
Figure 3B presents the Raman spectra of $\mathrm{SiO}_{2} @ \mathrm{C}$ and $\mathrm{MCS}$, respectively. For $\mathrm{SiO}_{2} / \mathrm{C}$, two prominent peaks at 1,588 and $1,360 \mathrm{~cm}^{-1}$ are observed, corresponding to the well-documented $\mathrm{G}$ band ( $\mathrm{sp}^{2}$ type graphitized carbon) and $\mathrm{D}$ band ( $\mathrm{sp}^{3}$ type disordered carbon), respectively (Li et al., 2010; Hu et al., 2020). The Raman spectra of the MCS also contain both G and D bands. Notably, the peak intensity ratio $\left(\mathrm{I}_{\mathrm{D}} / \mathrm{I}_{\mathrm{G}}\right)$ of MCS is calculated to be 0.88 , suggesting the disordered carbonaceous structure.

The nitrogen adsorption-desorption isotherms of $\mathrm{SiO}_{2} / \mathrm{C}$ precursors and MCS are shown in Figures 3C,D. The BrunauerEmmett-Teller (BET) specific surface area is calculated to be about $180.71 \mathrm{~m}^{2} \mathrm{~g}^{-1}$ for $\mathrm{SiO}_{2} / \mathrm{C}$ and $1106.32 \mathrm{~m}^{2} \mathrm{~g}^{-1}$ for MCS, respectively. The pore volume increases from 0.133 to $1.81 \mathrm{~cm}^{3} \mathrm{~g}^{-1}$ after etching. It found that etching away the silica template by HF greatly increases the specific surface area and pore volume of the carbon material. The $\mathrm{SiO}_{2} / \mathrm{C}$ exhibit pores centered from 2.1 to $33.2 \mathrm{~nm}$, as shown in Figure 3C. Furthermore, the pore size of MCS is mainly distributed in 3.4-20 nm (Figure 3D, insert), demonstrating the mesoporous structure, which is well in accordance with the TEM result. The porous structure of MCS could significantly accelerate the permeation of electrolytes into the active material and shorten the diffusion pathway of potassium ion ( $\mathrm{Wu}$ et al., 2019). Xray photoelectron spectroscopy (XPS) was carried out to further characterize the surface chemical composition of the MCS. As shown in Figures 3E,F, the high resolution C1s spectrum of MCS reveal the existence of the $\mathrm{C}-\mathrm{C}$ bond $(284.8 \mathrm{eV})$, oxygen groups including $\mathrm{C}-\mathrm{O}$ at $286.3 \mathrm{eV}$ and $\mathrm{C}=\mathrm{O}$ at $288.3 \mathrm{eV}$, respectively (Jayaramulu et al., 2018).

The electrochemical properties of the porous carbon materials were investigated in half-cells using metal potassium foil as both the counter and reference electrode. To evaluate the effect of different electrolytes on $\mathrm{K}$-ion storage performance, three electrolytes including $0.8 \mathrm{M} \mathrm{KPF}_{6}$ in $\mathrm{EC}$ : $\mathrm{DEC}=1: 1 \mathrm{vol} \%$ (KP-001), 1.0 M potassium bis(fluorosulfonyl)imide (KFSI) in 


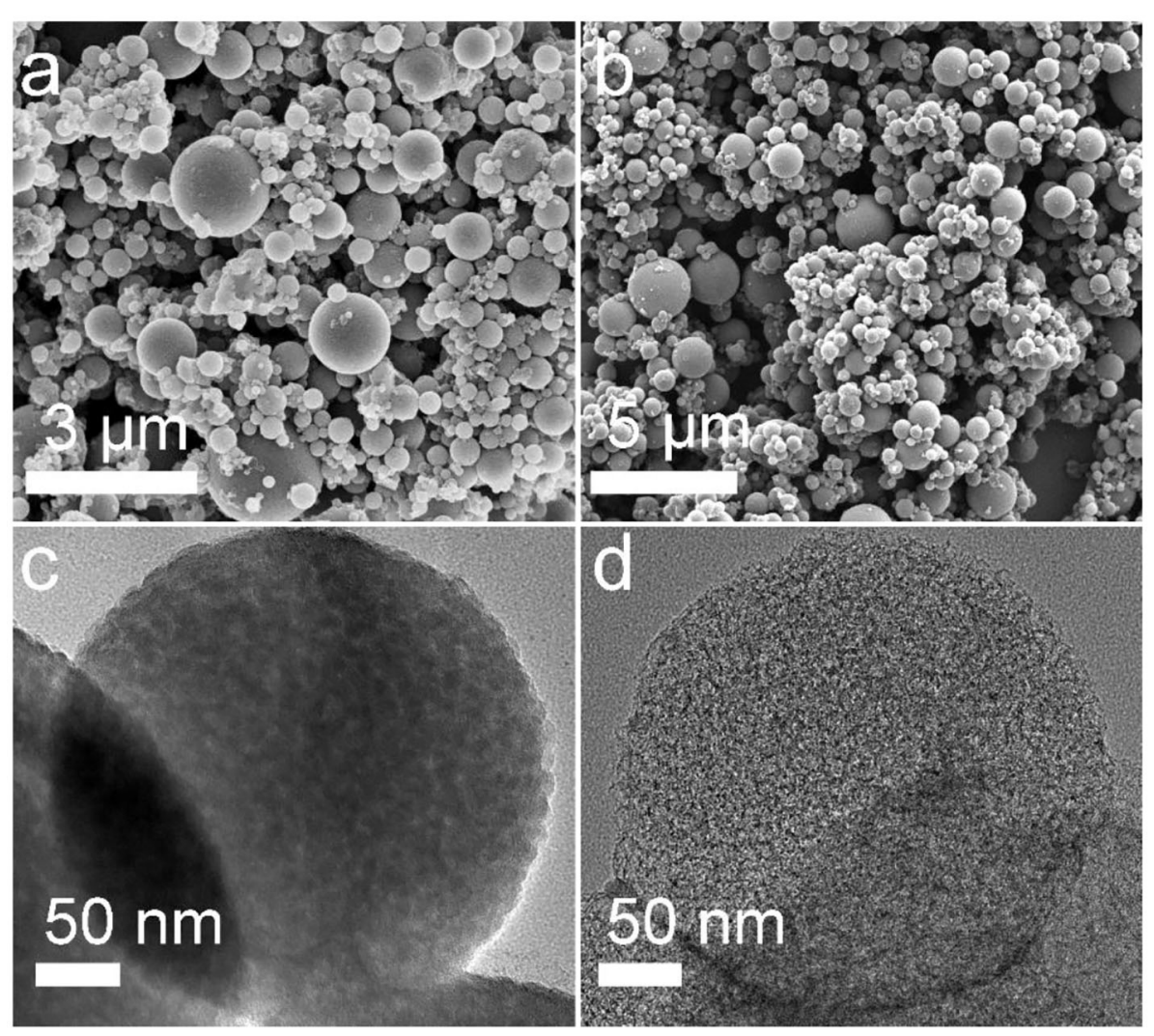

FIGURE 2 | FESEM images of (a) the $\mathrm{SiO}_{2} / \mathrm{C}$ composite, (b) the MCS material; TEM images of (c) $\mathrm{SiO}_{2} / \mathrm{C}$ composite, (d) as-prepared MCS material.

$\mathrm{EC}: \mathrm{DEC}=1: 1 \mathrm{vol} \%(\mathrm{KP}-044)$, and $1.0 \mathrm{M}$ potassium bis(trifluoromethylsulfonyl) imide (KTFSI) in TETRAGLYME $=100$ vol\% (KP-056) were investigated for galvanostatic cycling. Figures 4A-C exhibit the galvanostatic discharge-charge curves of MCS in KP-001, KP-044, and KP-056 at a current density of $50 \mathrm{~mA} \mathrm{~g}^{-1}$. The initial discharge and charge capacities are 1080.4 and $108.7 \mathrm{mAh} \mathrm{g}^{-1}$ for KP-001, 1603.1 and $170.5 \mathrm{mAh} \mathrm{g}^{-1}$ for KP-044, 607.5 and $187.3 \mathrm{mAh} \mathrm{g}^{-1}$ for KP-056, respectively. It is remarkable to note that all of them present a long voltage plateau at $0.8-1.0 \mathrm{~V}$, followed by a sloping curve down to the cutoff voltage of $0.01 \mathrm{~V}$ during the first discharge, which is a common phenomenon in carbon based anodes. The relatively large irreversible capacity loss can be related to the high specific surface area, causing irreversible electrolyte decomposition and the formation of solid electrolyte interphase (SEI) layer (Liu Y. et al., 2018), which leads to low Coulombic efficiency (CE). The first CE of MCS is 10.06, 10.63, and 30.38\% in KP-001, KP-044, and KP-056, respectively. The reversible specific capacity in the second cycle is $125.5 \mathrm{mAh} \mathrm{g}^{-1}$ for KP-001, $188.2 \mathrm{mAh} \mathrm{g}^{-1}$ for KP-044, $130.7 \mathrm{mAh} \mathrm{g}^{-1}$ for KP-056. From the charge-discharge curves, we can conclude that the materials show good capacity retention in KP-001 and KP-044. Especially, the MCS exhibits the highest specific capacity in KP-044 electrolyte. After the 20th cycle, the discharge capacity is up to $178.9 \mathrm{mAh} \mathrm{g}^{-1}$, giving rise to a high CE of $95.1 \%$.
As illustrated in Figure 4D, the porous carbon exhibits better cycling stability in KP-001 and KP-044 electrolyte. The discharge capacity is 124.9 and $154.5 \mathrm{mAh} \mathrm{g}^{-1}$ after 200 cycles at a current density of $50 \mathrm{~mA} \mathrm{~g}^{-1}$, respectively. High capacity of 84.9 and $105.3 \mathrm{mAh} \mathrm{g}^{-1}$ can be achieved after 500 cycle at a current density of $100 \mathrm{~mA} \mathrm{~g}^{-1}$, respectively. Compared with KP-001, KP-044 enables a higher capacity for the MCS anode, no obvious fading was observed over 500 cycles at $100 \mathrm{~mA} \mathrm{~g}^{-1}$. However, for KP-056 case, the carbon shows a fast capacity decay with a capacity of $104.4 \mathrm{mAh} \mathrm{g}^{-1}$ at 60 th cycle. Notably, the rate capability of the MCS is also the best for KP-044. Figure 4E shows the rate performance of the MCS electrode at the current density from $50 \mathrm{~mA} \mathrm{~g}^{-1}$ to $2 \mathrm{~A} \mathrm{~g}^{-1}$. For the KP-001 electrolyte, the carbon material exhibits the capacity of 156.2, 121.2, 95.5, $74.5,67.1$, and $51.1 \mathrm{mAh} \mathrm{g}^{-1}$, respectively, compared to KP-044 with the discharge capacity of $170.5,138.1,111.6,84.8,69.1$, and $55 \mathrm{mAh} \mathrm{g}^{-1}$ under the same current density. Furthermore, when the current density was returned back to $0.05 \mathrm{~A} \mathrm{~g}^{-1}$ after 60 cycles, the capacity could recover again, indicating the excellent reversibility of the MCS. The electrochemical performance of the mesoporous carbon in different electrolytes is also compared and summarized in Table 1. It should be noted that the potassium storage performance is comparable to those of many carbon based materials reported in literature (Table 2). 

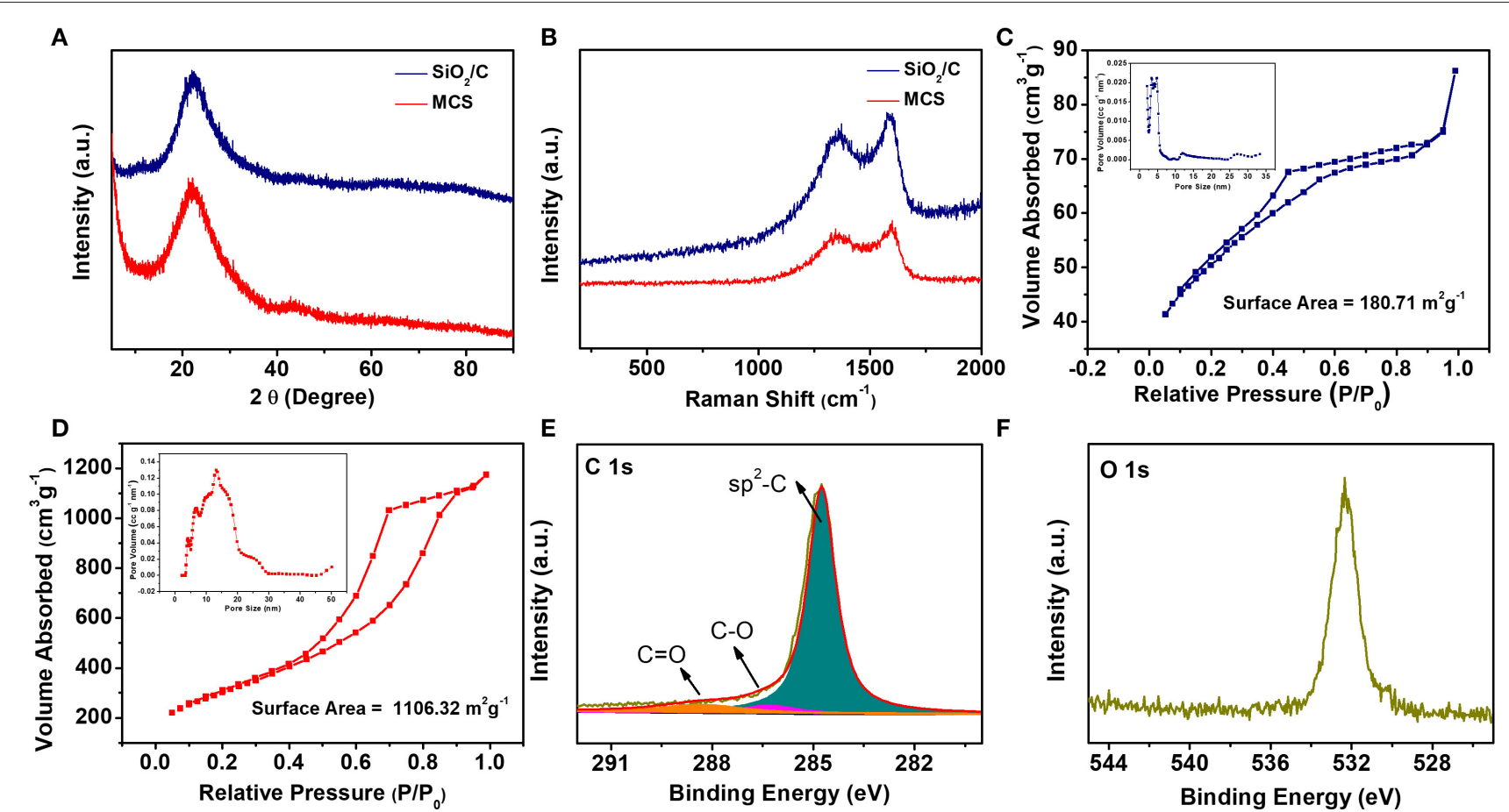

FIGURE 3 | (A) XRD patterns and (B) Raman spectra of $\mathrm{SiO}_{2} / \mathrm{C}$ and $\mathrm{MCS} ; \mathrm{N}_{2}$ adsorption-desorption isotherms and pore size distribution of (C) SiO $/$ /C and (D) MCS; XPS spectra of C 1s (E) and O 1s (F) for MCS.

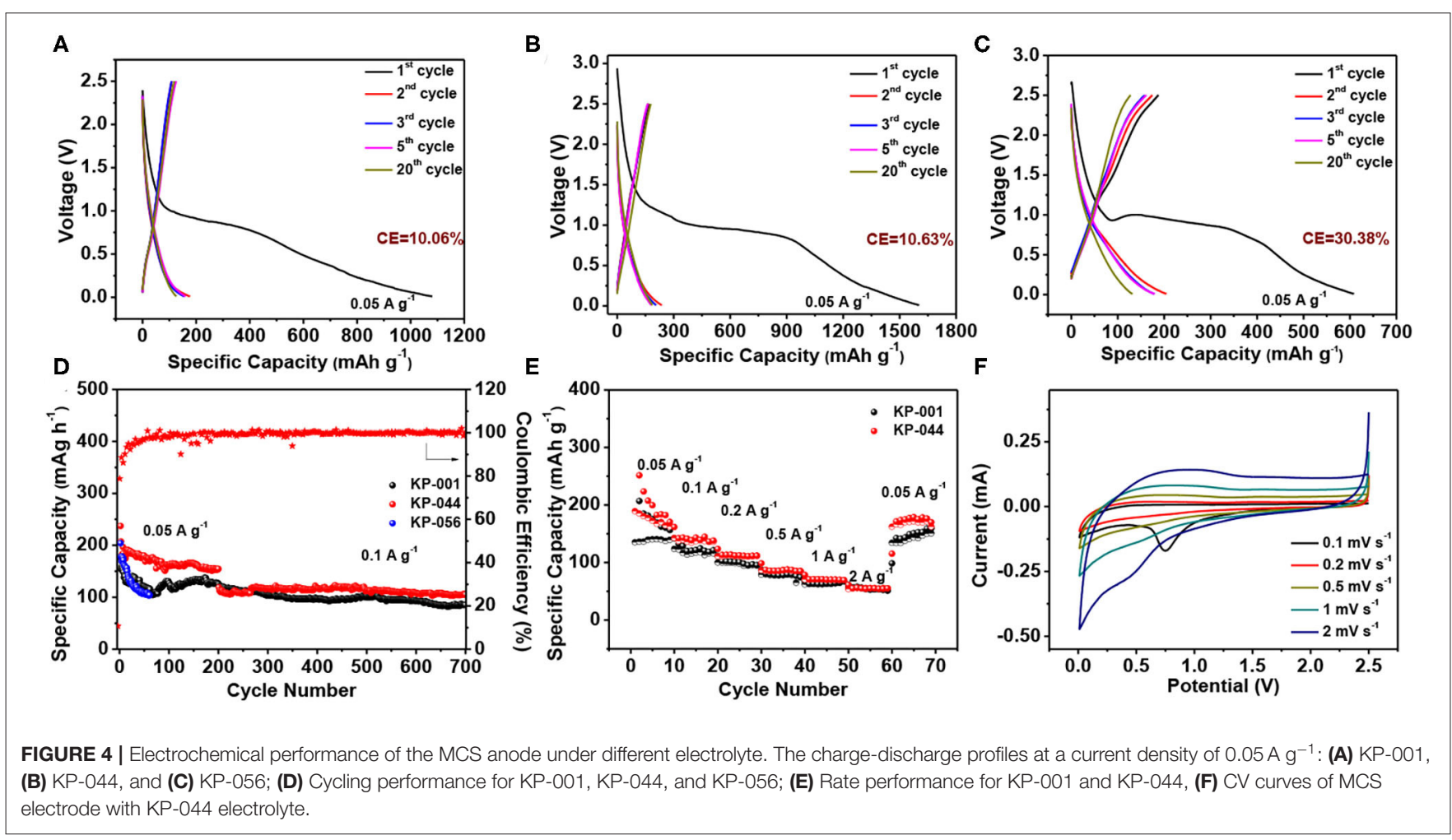

Figure 4F presents the CV curves of MCS electrode in KP-044 at different scan rate from 0.1 to $2.0 \mathrm{mV} \mathrm{s}^{-1}$ in the voltage range of $0.01-2.5 \mathrm{~V}$. The CV curve shows a significant broad peak at around $0.75 \mathrm{~V}$ during the first cathodic scan and then disappears in the subsequent cycles, which is due to the decomposition of the electrolyte and formation of SEI layer. The sharp peak 
located at around $0.1 \mathrm{~V}$ is related to the insertion of $\mathrm{K}$-ion into carbon (Hu et al., 2019). After the first cycle, the shape could be well-maintained with the increasing scan rate, indicating its excellent stability. Such good electrochemical potassium storage performance can be attributed to its unique porous architecture for the accessibility for electrolyte and electron transfer with enhanced conductivity. Moreover, the large specific surface area could provide sufficient space for $\mathrm{K}$ ion reaction at interface. Most importantly, previous reports have suggested that KSFI saltbased electrolyte could form a stable and robust SEI layer on electrode surface, and effectively suppress $\mathrm{K}$ dendrite growth and inhibit electrolyte decomposition to boost stable performance for K storage (Xiao et al., 2017; Wang H. et al., 2019).

To further demonstrate the effect of different electrolytes, electrochemical impedance spectroscopy (EIS) was conducted in the frequency range from $100 \mathrm{kHz}$ to $0.01 \mathrm{~Hz}$. As shown in Figure 5, the Nyquist plots consist of a depressed semicircle in the high- and middle-frequency regions and a straight line in the low-frequency region, which correspond to the SEI film and contact resistance, charge-transfer resistance $(R \mathrm{ct})$ and the diffusion of $\mathrm{K}$-ion ions into bulk electrode, respectively ( $\mathrm{Li}$ et al.,

TABLE 1 | Electrochemical performance of the MCS anode by using different electrolytes.

\begin{tabular}{|c|c|c|c|c|c|c|c|}
\hline \multirow[t]{2}{*}{ Electrolyte } & \multirow[t]{2}{*}{$\begin{array}{l}\text { Initial } \\
\text { CE }\end{array}$} & \multicolumn{3}{|c|}{$\begin{array}{l}\text { Specific capacity } \\
\left(\mathrm{mAh} \mathrm{g} \mathrm{g}^{-1}\right) \\
50 \mathrm{~mA} \mathrm{~g}^{-1}\end{array}$} & \multicolumn{3}{|c|}{$\begin{array}{l}\text { Rate performance } \\
\qquad\left(\mathrm{mAh} \mathrm{g}^{-1}\right)\end{array}$} \\
\hline & & $\begin{array}{l}2 \text { rd } \\
\text { cycle }\end{array}$ & $\begin{array}{l}\text { 60th } \\
\text { cycle }\end{array}$ & $\begin{array}{l}\text { 200th } \\
\text { cycle }\end{array}$ & $\begin{array}{c}200 \mathrm{~mA} \\
\mathrm{~g}^{-1}\end{array}$ & $\begin{array}{c}500 \mathrm{~mA} \\
\mathrm{~g}^{-1}\end{array}$ & $\begin{array}{c}1,000 \mathrm{~mA} \\
\mathrm{~g}^{-1}\end{array}$ \\
\hline KP-044 & $10.63 \%$ & 188.2 & 174.2 & 154.5 & 111.6 & 84.8 & 69.1 \\
\hline KP-001 & $10.06 \%$ & 125.5 & 114.4 & 124.9 & 95.5 & 74.5 & 67.1 \\
\hline KP-056 & $30.38 \%$ & 130.7 & 104.4 & - & - & - & - \\
\hline
\end{tabular}

2018; Wang et al., 2018; Liu Y. et al., 2019; Zhang et al., 2019a,b). Figure 5 compares the EIS spectra of the carbon electrode before and after 5 cycles in KP-001 and KP-044 electrolytes. All the electrodes exhibit an increased Rct after cycling, consistent with the results reported (Li et al., 2018).

\section{CONCLUSION}

In summary, mesoporous carbon spheres have been synthesized through a simple aerosol spray method by using low cost sucrose and silica colloid as precursors. The as-prepared porous carbon exhibited a well-defined spherical morphology with a size ranging from $100 \mathrm{~nm}$ to $2 \mu \mathrm{m}$. The elaborately designed nanostructure of the carbon spheres with high electrical conductivity and high surface area facilitates fast potassium ions

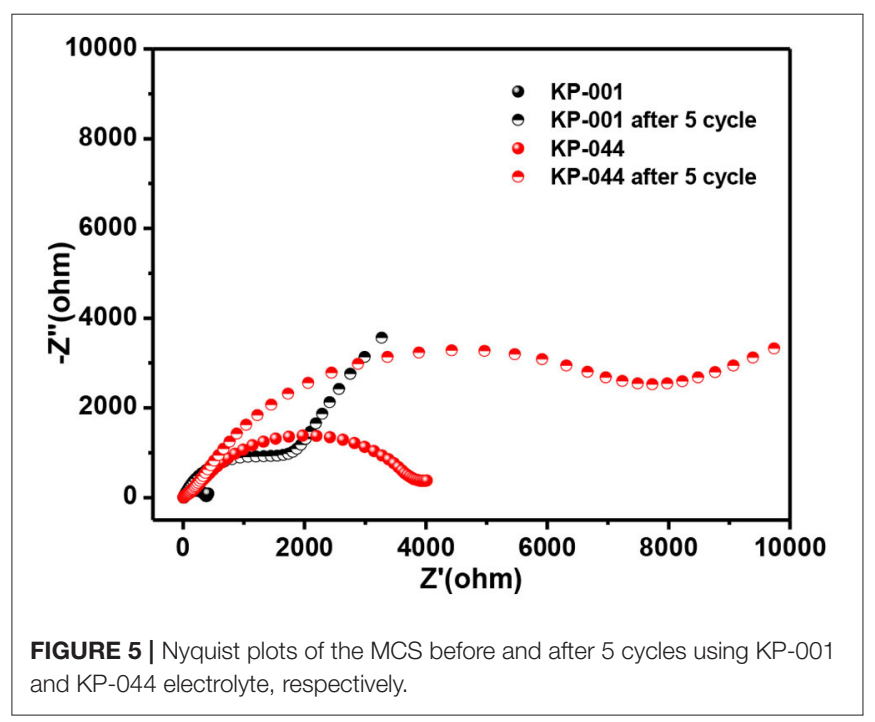

TABLE 2 | Electrochemical characteristics of reported carbon materials for KIBs in literature and our work.

\begin{tabular}{|c|c|c|c|c|c|c|c|}
\hline Anode materials & $\begin{array}{l}\text { Specific surface } \\
\text { area }\left(\mathrm{m}^{2} \mathrm{~g}^{-1}\right)\end{array}$ & Pore size (nm) & ICE (\%) & $\begin{array}{l}\text { Current density } \\
\qquad\left(\mathrm{mA} \mathrm{g}^{-1}\right)\end{array}$ & $\begin{array}{l}\text { Specific capacity } \\
\qquad\left(m A h \mathrm{~g}^{-1}\right)\end{array}$ & Cycle life & References \\
\hline Ordered mesoporous carbon & 1,089 & $0-20$ & 63.6 & 50 & 257.4 & 100 & Wang et al., 2018 \\
\hline CNTs/GCF & 52.7 & $0-20$ & 24 & 100 & 228 & 800 & Zeng et al., 2019 \\
\hline Hard carbon & 354 & $1.0-4.0$ & 73 & 200 & 175 & 80 & He et al., 2018 \\
\hline Crumbled graphene & 318 & & 39 & 40 & 340 & & Lee et al., 2020 \\
\hline OMFC-30 & & & 31.4 & 50 & 277 & 100 & $\begin{array}{l}\text { Zhang R. et al., } \\
2019\end{array}$ \\
\hline HNCS & 163.3 & & 35 & 100 & 198 & 200 & Sun et al., 2020 \\
\hline $\mathrm{N}-\mathrm{HCN}$ & 228.0 & & & 50 & 241 & 100 & Ruan et al., 2019 \\
\hline MCS & 1,106 & $3.4-20$ & 10.63 & 50 & 154.5 & 200 & This work \\
\hline
\end{tabular}


and electrons transport, which make the mesoporous carbon sphere remarkable $\mathrm{K}$ storage property in terms of moderate reversible capacity, rate capability, and excellent cyclic stability. Furthermore, the KFSI electrolyte enables the porous carbon excellent electrochemical cyclability and improved capacity at high rate due to the formation of a stable and robust SEI layer. Encouragingly, the porous carbon material exhibited a high specific capacity of $154.5 \mathrm{mAh} \mathrm{g}^{-1}$ after 200 cycles at a current density at $50 \mathrm{~mA} \mathrm{~g}^{-1}$, and the capacity could be achieved at 105.3 $\mathrm{mAh} \mathrm{g}^{-1}$ after 500 cycles at a rate of $100 \mathrm{~mA} \mathrm{~g}^{-1}$.

\section{EXPERIMENTAL}

\section{Materials Synthesis}

Typically, $15 \mathrm{~g}$ of colloidal silica (particles size: 10-20 nm) kindly provided by Nissan Chemical America Corporation (Houston, TX) was firstly mixed with $17 \mathrm{~g} 0.1 \mathrm{~mol} \mathrm{~L}^{-1} \mathrm{HCl}$ aqueous solution. Then, $4 \mathrm{~g}$ sucrose was added to obtain a homogeneous solution under magnetic stirring. The precursor solution was next atomized by using nitrogen as a carrier gas with the heating zone maintaining at a constant temperature of $450^{\circ} \mathrm{C}$. The collected samples were further annealed at $500^{\circ} \mathrm{C}$ for $5 \mathrm{~h}$ and $900^{\circ} \mathrm{C}$ for another $5 \mathrm{~h}$ under the $\mathrm{N}_{2}$ atmosphere with a heating rate of $10^{\circ} \mathrm{C} \mathrm{min}{ }^{-1}$ to obtained $\mathrm{SiO}_{2} /$ carbon composite. The product obtained was subsequently washed with $5 \% \mathrm{HF}$ and distilled water to remove the silica templates. After drying at $60^{\circ} \mathrm{C}$ in vacuum for $12 \mathrm{~h}$, mesoporous carbon spheres were collected.

\section{Characterization}

The crystal structure of the experimentally prepared porous carbon spheres was characterized by X-ray diffraction (XRD, Rigaku d/max PC2500) in the range of 5 to $90^{\circ}$. The morphology and microstructure characteristics of the samples were observed using a field emission scanning electron microscope (FESEM, JSM-7800F) and a high resolution transmission electron microscope (TEM, JEM-2100, JEOL). The pore size and specific surface area of the sample were analyzed using an Isorb-HP2 analyzer (Quantachrome Instruments) to measure the $\mathrm{N}_{2}$ adsorption/desorption isotherms at $77 \mathrm{~K}$ under liquid nitrogen. The X-ray photoelectron spectrum (XPS) was collected on a ESCALAB 250Xi spectrometer with a mono $\mathrm{Al} \mathrm{Ka}$ radiation. The Raman spectra were tested by a Renishaw 2000 System.

\section{Electrochemical Measurement}

For the electrochemical measurements, the as-prepared materials were mixed with acetylene black and sodium alginate in a weight ratio of 70:15:15. The mixture was prepared to form uniform

\section{REFERENCES}

Chen, G., Wan, H., Ma, W., Zhang, N., Cao, Y., Liu, X., et al. (2020). Layered metal hydroxides and their derivatives: controllable synthesis, chemical exfoliation, and electrocatalytic applications. Adv. Energy Mater. 10:1902535. doi: 10.1002/aenm. 201902535 slurry in deionized water and spread onto copper foil current collector by using a doctor-blade technique. After drying at $70^{\circ} \mathrm{C}$ in vacuum, the foil was roll-pressed and cut into circular pieces. Coin-cells were assembled in an argon-filled glove box using metal potassium as the counter electrode and Whatman ${ }^{\circledR}$ glass fiber as the separator. Three different electrolytes were used, including $0.8 \mathrm{M} \mathrm{KPF}_{6}$ in EC: $\mathrm{DEC}=1: 1 \mathrm{vol} \%(\mathrm{KP}-$ 001), $1.0 \mathrm{M}$ KFSI in EC: DEC $=1: 1 \mathrm{vol} \%(\mathrm{KP}-044), 1.0 \mathrm{M}$ KTFSI in TETRAGLYME $=100$ vol\% (KP-056). Galvanostatic charge/discharge cycles were tested on a cell test instrument (CT2001A, LAND Electronic Co., China) at a current density of $50 \mathrm{~mA} \mathrm{~g}^{-1}$ between 0.01 and $2.5 \mathrm{~V}$. The specific capacity was calculated based on the weight of the mesoporous carbon spheres. Cyclic voltammetry (CV) was performed using a CHI 660E electrochemical workstation (CH Instruments, Chenhua, China) at a scan rate of $0.1 \mathrm{mV} \mathrm{s}^{-1}$ within the voltage range of $0.01-$ $2.5 \mathrm{~V}$. Electrochemical impedance spectra (EIS) were collected in the frequency range from $100 \mathrm{kHz}$ to $0.1 \mathrm{~Hz}$ on the $\mathrm{CHI}$ $660 \mathrm{E}$ electrochemical workstation with a voltage perturbation of $5 \mathrm{mV}$.

\section{DATA AVAILABILITY STATEMENT}

The raw data supporting the conclusions of this article will be made available by the authors, without undue reservation.

\section{AUTHOR CONTRIBUTIONS}

YG, LC, and PN designed the experimental work and co-wrote the manuscript. YG and PN conducted the materials synthesis. $\mathrm{BR}, \mathrm{YG}$, and HW conducted the characterization. YG, JL, and LL performed the electrochemical measurements in potassium ion batteries and the related data processing. TX revised the manuscript. All authors analyzed the results and commented on the manuscript.

\section{FUNDING}

The work was supported by the National Natural Science Foundation of China (no. 51802111), Funds for Special Projects of the Central Government in Guidance of Local Science and Technology Development, Funding of Jilin Province Development and Reform Commission (no. 2020C026-2), Research Program on Science and Technology from the Education Department of Jilin Province (no. JJKH20190997KJ), and Funding of JLNU Innovation Program for Graduate Education (no. 201919). 
Hosaka, T., Kubota, K., Hameed, A. S., and Komaba, S. (2020). Research development on K-Ion batteries. Chem. Rev. 120, 6358-6466. doi: 10.1021 /acs.chemrev.9b00463

Hu, X., Liu, Y., Chen, J., Yi, L., Zhan, H., and Wen, Z. (2019). Fast Redox kinetics in Bi-Heteroatom doped 3D porous carbon nanosheets for high-performance hybrid potassium-ion battery capacitors. Adv. Energy Mater. 9:1901533. doi: 10.1002/aenm.201901533

Hu, X., Zhong, G., Li, J., Liu, Y., Yuan, J., Chen, J., et al. (2020). Hierarchical porous carbon nanofibers for compatible anode and cathode of potassium-ion hybrid capacitor. Energy Environ. Sci. 13: 2431-2440. doi: 10.1039/D0EE00477D

Huang, H., Xu, R., Feng, Y., Zeng, S., Jiang, Y., Wang, H., et al. (2020). Sodium/potassium-ion batteries: boosting the rate capability and cycle life by combining morphology, defect and structure engineering. Adv. Mater. 32:1904320. doi: 10.1002/adma.201904320

Jayaramulu, K., Dubal, D. P., Nagar, B., Ranc, V., Tomanec, O., Petr, M., et al. (2018). Ultrathin hierarchical porous carbon nanosheets for high-performance supercapacitors and redox electrolyte energy storage. Adv. Mater. 30:1705789. doi: 10.1002/adma.201705789

Jian, Z., Luo, W., and Ji, X. (2015). Carbon electrodes for K-ion batteries. J. Am. Chem. Soc. 137, 11566-11569. doi: 10.1021/jacs.5b06809

Jiang, L., Lu, Y., Zhao, C., Liu, L., Zhang, J., Zhang, Q., et al. (2019). Building aqueous K-ion batteries for energy storage. Nat. Energy 4, 495-503. doi: 10.1038/s41560-019-0388-0

Komaba, S., Hasegawa, T., Dahbi, M., and Kubota, K. (2015). Potassium intercalation into graphite to realize high-voltage/high-power potassium-ion batteries and potassium-ion capacitors. Electrochem. Commun. 60, 172-175. doi: 10.1016/j.elecom.2015.09.002

Le, Z., Liu, F., Nie, P., Li, X., Liu, X., Bian, Z., et al. (2017). Pseudocapacitive sodium storage in mesoporous single-crystal-like $\mathrm{TiO}_{2}$-graphene nanocomposite enables high-performance sodium-ion capacitors. ACS Nano 11, 2952-2960. doi: 10.1021/acsnano.6b08332

Lee, B., Kim, M., Kim, S., Nanda, J., Kwon, S. J., Jang, H. D., et al. (2020). High capacity adsorption-dominated potassium and sodium ion storage in activated crumpled graphene. Adv. Energy Mater. 10:1903280. doi: 10.1002/aenm.201903280

Lei, K., Wang, C., Liu, L., Luo, Y., Mu, C., Li, F., et al. (2018). A Porous network of bismuth used as the anode material for high-energy-density potassiumion batteries. Angew. Chem. Int. Ed. 57, 4687-4691. doi: 10.1002/anie.2018 01389

Li, D., Ren, X., Ai, Q., Sun, Q., Zhu, L., Liu, Y., et al. (2018). Facile Fabrication of nitrogen-doped porous carbon as superior anode material for potassium-ion batteries. Adv. Energy Mater. 8:1802386. doi: 10.1002/aenm.2018 02386

Li, J., Li, Y., Ma, X., Zhang, K., Hu, J., Yang, C., et al. (2020b). A honeycomblike nitrogen-doped carbon as high-performance anode for potassium-ion batteries. Chem. Eng. J. 384:123328. doi: 10.1016/j.cej.2019.123328

Li, J., Rui, B., Wei, W., Nie, P., Chang, L., Le, Z., et al. (2020a). Nanosheets assembled layered $\mathrm{MoS}_{2} / \mathrm{MX}$ ene as high performance anode materials for potassium ion batteries. J. Power Sources 449:227481. doi: 10.1016/j.jpowsour.2019.227481

Li, L., Nie, P., Chen, Y., and Wang, J. (2019). Novel acetic acid induced Na-rich Prussian blue nanocubes with iron defects as cathodes for sodium ion batteries. J. Mater. Chem. A 7, 12134-12144. doi: 10.1039/C9TA01965K

Li, X., Chen, G., Le, Z., Li, X., Nie, P., Liu, X., et al. (2019). Welldispersed phosphorus nanocrystals within carbon via high-energy mechanical milling for high performance lithium storage. Nano Energy 59, 464-471. doi: 10.1016/j.nanoen.2019.02.061

$\mathrm{Li}, \mathrm{Y}$., Lv, X., Lu, J., and Li, J. (2010). Preparation of $\mathrm{SnO}_{2}$-nanocrystal/graphenenanosheets composites and their lithium storage ability. J. Phys. Chem. C 114, 21770-21774. doi: 10.1021/jp1050047

Liu, C., Xiao, N., Li, H., Dong, Q., Wang, Y., Li, H., et al. (2020). Nitrogendoped soft carbon frameworks built of well-interconnected nanocapsules enabling a superior potassium-ion batteries anode. Chem. Eng. J. 382:121759. doi: 10.1016/j.cej.2019.05.120

Liu, J., Li, F., Liu, W., and Li, X. (2019b). Effect of calcination temperature on the microstructure of vanadium nitride/nitrogen-doped graphene nanocomposites as anode materials in electrochemical capacitors. Inorg. Chem. Front. 6, 164-171. doi: 10.1039/C8QI01071D
Liu, J., Ren, X., Kang, X., He, X., Wei, P., Wen, Y., et al. (2019a). Fabrication of nitrogen-rich three-dimensional porous carbon composites with nanosheets and hollow spheres for efficient supercapacitors. Inorg. Chem. Front. 6, 2082-2089. doi: 10.1039/C9QI00536F

Liu, M., Chang, L., Wang, J., Li, J., Jiang, J., Pang, G., et al. (2020). Hierarchical N-doped carbon nanosheets submicrospheres enable superior electrochemical properties for potassium ion capacitors. J. Power Sources 469:228415. doi: 10.1016/j.jpowsour.2020.228415

Liu, X., Tian, Y., Cao, X., Li, X., Le, Z., Zhang, D., et al. (2018). Aerosolassisted synthesis of spherical $\mathrm{Sb} / \mathrm{C}$ composites as advanced anodes for lithium ion and sodium ion batteries. ACS Appl. Energy Mater. 1, 6381-6387. doi: 10.1021/acsaem. 8 b01353

Liu, Y., Fang, Y., Zhao, Z., Yuan, C., and Lou, X. W. (2019). A ternary $\mathrm{Fe}_{1-\mathrm{x}} \mathrm{S} @$ Porous carbon nanowires/reduced graphene oxide hybrid film electrode with superior volumetric and gravimetric capacities for flexible sodium ion batteries. Adv. Energy Mater. 9:1803052. doi: $10.1002 /$ aenm.201803052

Liu, Y., Sun, Z., Sun, X., Lin, Y., Tan, K., Sun, J., et al. (2020). Construction of Hierarchical nanotubes assembled from ultrathin $\mathrm{V}_{3} \mathrm{~S}_{4} @ \mathrm{C}$ nanosheets towards alkali-ion batteries with ion-dependent electrochemical mechanisms. Angew. Chem., Int. Ed. 59, 2473-2482. doi: 10.1002/anie.201913343

Liu, Y., Tai, Z., Zhang, J., Pang, W. K., Zhang, Q., Feng, H., et al. (2018). Boosting potassium-ion batteries by few-layered composite anodes prepared via solution-triggered one-step shear exfoliation. Nat. Commun. 9:3645. doi: 10.1038/s41467-018-05786-1

Lu, Y., Fan, H., Stump, A., Ward, T. L., Rieker, T., and Brinker, C. J. (1999). Aerosol-assisted self-assembly of mesostructured spherical nanoparticles. Nature 398, 223-226. doi: 10.1038/18410

Luo, W., Wan, J., Ozdemir, B., Bao, W., Chen, Y., Dai, J., et al. (2015). Potassium ion batteries with graphitic materials. Nano Lett. 15, 7671-7677. doi: 10.1021/acs.nanolett.5b03667

Nie, P., Le, Z., Chen, G., Liu, D., Liu, X., Wu, H. B., et al. (2018b). Graphene caging silicon particles for high-performance lithium-ion batteries. Small. 14:1800635. doi: 10.1002/smll.201800635

Nie, P., Liu, X., Fu, R., Wu, Y., Jiang, J., Dou, H., et al. (2017). Mesoporous silicon anodes by using polybenzimidazole derived pyrrolic N-Enriched carbon toward high-energy Li-ion batteries. ACS Energy Lett. 2, 1279-1287. doi: 10.1021/acsenergylett.7b00286

Nie, P., Xu, G., Jiang, J., Dou, H., Wu, Y., Zhang, Y., et al. (2018a). Aerosolspray pyrolysis toward preparation of nanostructured materials for batteries and supercapacitors. Small Methods 2:1700272. doi: 10.1002/smtd.201700272

Okubo, M., Sugahara, A., Kajiyama, S., and Yamada, A. (2018). MXene as a charge storage host. Acc. Chem. Res. 51, 591-599. doi: 10.1021/acs.accounts.7b00481

Peng, Y., Le, Z., Wen, M., Zhang, D., Chen, Z., Wu, H. B., et al. (2017). Mesoporous single-crystal-like $\mathrm{TiO}_{2}$ mesocages threaded with carbon nanotubes for high-performance electrochemical energy storage. Nano Energy 35, 44-51. doi: 10.1016/j.nanoen.2017.03.003

Qin, J., Kheimeh Sari, H. M., He, C., and Li, X. (2019). A hybrid energy storage mechanism of carbonous anodes harvesting superior rate capability and long cycle life for sodium/potassium storage. J. Mater. Chem. A 7, 3673-3681. doi: 10.1039/C8TA12040D

Ruan, J., Wu, X., Wang, Y., Zheng, S., Sun, D., Song, Y., et al. (2019). Nitrogendoped hollow carbon nanospheres towards the application of potassium ion storage. J. Mater. Chem. A 7, 19305-19315. doi: 10.1039/C9TA05205D

Sultana, I., Ramireddy, T., Rahman, M. M., Chen, Y., and Glushenkov, A. M. (2016). Tin-based composite anodes for potassium-ion batteries. Chem. Commun. 52, 9279-9282. doi: 10.1039/C6CC03649J

Sun, J., Guo, L., Sun, X., Zhang, J., Hou, L., Li, L., et al. (2019). One-Dimensional nanostructured pseudocapacitive materials: design, synthesis and applications in supercapacitors. Batteries Supercaps 2, 820-841. doi: 10.1002/batt. 201900021

Sun, Y., Zhang, Y., Xing, Z., Wei, D., Ju, Z., and Zhuang, Q. (2020). A hollow neuronal carbon skeleton with ultrahigh pyridinic $\mathrm{N}$ content as a selfsupporting potassium-ion battery anode. Sustain Energy Fuels 4, 1216-1224. doi: 10.1039/C9SE00889F

Tang, X., Zhou, D., Li, P., Guo, X., Sun, B., Liu, H., et al. (2020). MXenebased dendrite-free potassium metal batteries. Adv. Mater. 32:1906739. doi: 10.1002/adma.201906739 
Tao, L., Liu, L., Chang, R., He, H., Zhao, P., and Liu, J. (2020). Structural and interface design of hierarchical porous carbon derived from soybeans as anode materials for potassium-ion batteries. J. Power Sources 463:228172. doi: 10.1016/j.jpowsour.2020.228172

Wang, F., Chen, G., Zhang, N., Liu, X., and Ma, R. (2019). Engineering of carbon and other protective coating layers for stabilizing silicon anode materials. Carbon Energy. 1, 219-245. doi: 10.1002/cey2.24

Wang, H., Yu, D., Wang, X., Niu, Z., Chen, M., Cheng, L., et al. (2019). Electrolyte chemistry enables simultaneous stabilization of potassium metal and alloying anode for potassium-ion batteries. Angew. Chem., Int. Ed. 58, 16451-16455. doi: 10.1002/anie.201908607

Wang, W., Zhou, J., Wang, Z., Zhao, L., Li, P., Yang, Y., et al. (2018). Short-range order in mesoporous carbon boosts potassium-ion battery performance. $A d v$. Energy Mater. 8:1701648. doi: 10.1002/aenm.201701648

Wu, X., Lam, C. W. K., Wu, N., Pang, S.-S., Xing, Z., Zhang, W., et al. (2019). Multiple templates fabrication of hierarchical porous carbon for enhanced rate capability in potassium-ion batteries. Mater. Today Energy 11, 182-191. doi: 10.1016/j.mtener.2018.11.009

Wu, X., Leonard, D. P., and Ji, X. (2017). Emerging non-aqueous potassiumion batteries: challenges and opportunities. Chem. Mater. 29, 5031-5042. doi: 10.1021/acs.chemmater.7b01764

Xiao, N., McCulloch, W. D., and Wu, Y. (2017). Reversible dendrite-free potassium plating and stripping electrochemistry for potassium secondary batteries. J. Am. Chem. Soc. 139, 9475-9478. doi: 10.1021/jacs.7b04945

Zeng, S., Zhou, X., Wang, B., Feng, Y., Xu, R., Zhang, H., et al. (2019). Freestanding CNT-modified graphitic carbon foam as a flexible anode for potassium ion batteries. J. Mater. Chem. A 7, 15774-15781. doi: 10.1039/C9TA03245B

Zhang, R., Li, H., Li, R., Wei, D., Kang, W., Ju, Z., et al. (2019). Boosting the potassium-ion storage performance of a carbon anode by chemically regulating oxygen-containing species. Chem. Commun. 55, 14147-14150. doi: 10.1039/C9CC07585B

Zhang, W., Cao, Z., Wang, W., Alhajji, E., Emwas, A.-H., Costa, P. M. F. J., et al. (2020). A Site-selective doping strategy of carbon anodes with remarkable K-ion storage capacity. Angew. Chem. Int. Ed. 59, 4448-4455 doi: 10.1002/anie.201913368

Zhang, W., Liu, Y., and Guo, Z. (2019a). Approaching high-performance potassium-ion batteries via advanced design strategies and engineering. Sci. Adv. 5:eaav7412. doi: 10.1126/sciadv.aav7412

Zhang, W., Mao, J., Li, S., Chen, Z., and Guo, Z. (2017). Phosphorus-based alloy materials for advanced potassium-ion battery anode. J. Am. Chem. Soc. 139, 3316-3319. doi: 10.1021/jacs.6b12185

Zhang, W., Ming, J., Zhao, W., Dong, X., Hedhili, M. N., Costa, P. M. F. J., et al. (2019b). Graphitic nanocarbon with engineered defects for highperformance potassium-ion battery anodes. Adv. Funct. Mater. 29:1903641. doi: 10.1002/adfm.201903641

Zhao, R., Di, H., Hui, X., Zhao, D., Wang, R., Wang, C., et al. (2020). Self-assembled $\mathrm{Ti}_{3} \mathrm{C}_{2}$ MXene and $\mathrm{N}$-rich porous carbon hybrids as superior anodes for high-performance potassium-ion batteries. Energy Environ. Sci. 13, 246-257. doi: 10.1039/C9EE03250A

Zheng, J., Yang, Y., Fan, X., Ji, G., Ji, X., Wang, H., et al. (2019). Extremely stable antimony-carbon composite anodes for potassium-ion batteries. Energy Environ. Sci. 12, 615-623. doi: 10.1039/C8EE02836B

Zhou, J., Liu, Y., Zhang, S., Zhou, T., and Guo, Z. (2020). Metal chalcogenides for potassium storage. InfoMat 2, 437-465. doi: 10.1002/inf2.12101

Conflict of Interest: The authors declare that the research was conducted in the absence of any commercial or financial relationships that could be construed as a potential conflict of interest.

Copyright (C) 2020 Guo, Li, Wang, Chang, Rui, Lin, Xu and Nie. This is an open-access article distributed under the terms of the Creative Commons Attribution License (CC $B Y)$. The use, distribution or reproduction in other forums is permitted, provided the original author(s) and the copyright owner(s) are credited and that the original publication in this journal is cited, in accordance with accepted academic practice. No use, distribution or reproduction is permitted which does not comply with these terms. 